\title{
C4 cervical spine osteoblastoma associated with secondary aneurysmal bone cyst in an adolescent patient: 2-year follow-up
}

\author{
Nitesh Gahlot $\mathbb{B}^{1} \cdot$ Divesh Jalan $^{2} \cdot$ Poonam Elhence $^{3}$
}

Received: 12 July 2019 / Revised: 26 September 2019 / Accepted: 6 October 2019

(c) International Spinal Cord Society 2019

\begin{abstract}
Introduction Osteoblastoma and aneurysmal bone cyst $(\mathrm{ABC})$ are rare bone tumors with individual prevalence of $<1 \%$. Their combined occurrence is a rare subclass of tumors in the spinal column with only a few cases reported in literature. Case presentation The present case is a rare combination of aggressive osteoblastoma with secondary aneurysmal bone cyst masquerading as neck pain, arising from cervical C4 vertebra in a 19-year-old male. The patient presented with complaints of neck pain for 7 months, gradual in onset, dull, aching, and progressively increasing in severity. Neurological examination was normal. Radiology showed an expansile lytic mass arising from the posterior elements of $\mathrm{C} 4$ vertebra involving the left lateral mass. Piecemeal total removal was done and a posterior fusion from C3 to C5 was performed for stability. Histopathology confirmed the osteoblastoma with a secondary aneurysmal bone cyst. Postoperatively the patient recovered well, and no recurrence was seen on a 2-year follow-up.

Discussion Simultaneous presence of an osteoblastoma with a secondary ABC arising from various bones, such as cranial fossa, ethmoid sinus, skull, and mandibular condyle, has rarely been reported. It is often diagnosed late due to nonspecific symptoms; but it has a good prognosis if early and complete resection is performed. Thorough surgical excision is always a challenge in spine cases due to surrounding important structures and meticulousness is required to prevent any recurrences. Hence, we recommend a surgical team comprising both spine and musculoskeletal oncologic surgeons to achieve best results.
\end{abstract}

\section{Introduction}

The osteoblastoma and aneurysmal bone cyst $(\mathrm{ABC})$ are rare bone tumors with individual prevalence of $<1 \%$ [1]. Their combined occurrence is a rare subclass of tumors in the spinal column with only a few cases reported in literature. We report a case with histologically proven osteoblastoma associated with secondary $\mathrm{ABC}$ arising from $\mathrm{C} 4$ cervical vertebra and eroding into adjacent vertebrae with a 2-year follow-up. To our knowledge, only

Nitesh Gahlot

doc.nitesh@gmail.com

1 Department of Orthopedics, All India Institute of Medical Sciences (AIIMS), Jodhpur, Rajasthan, India

2 Department of Orthopedics, Safdurjung and VMMC, New Delhi, India

3 Department of Pathology, All India Institute of Medical Sciences (AIIMS), Jodhpur, Rajasthan, India four such cases have been documented in recent literature [2-5]. Early and correct diagnosis and complete removal can be a challenge given a protracted clinical presentation and cervical location that makes achieving a clean margin difficult.

\section{Case presentation}

The patient is a 19-year-old male, who presented to us in the outpatient department with a 1-year history of neck pain. The pain was dull and aching in character with no diurnal variation and was located on the posterior aspect of his neck in left paraspinal location. A diffuse, tender, nonfluctuant swelling was present at the site of tenderness. All neck movements were painfully restricted.

Radiographs, CT scan, and MRI showed a heterogeneous expansile mass arising out of the $\mathrm{C} 4$ left lamina posteriorly, also involving the lateral mass and encroaching into the canal (Figs. 1-3). Based upon imaging, osteoblastoma seemed the most probable diagnosis. The 
Fig. 1 Preoperative radiographs showing the tumor mass arising from the posterior aspect of $\mathrm{C} 4$ cervical vertebrae. No interval change was seen compared with plain radiographs taken 1 year back

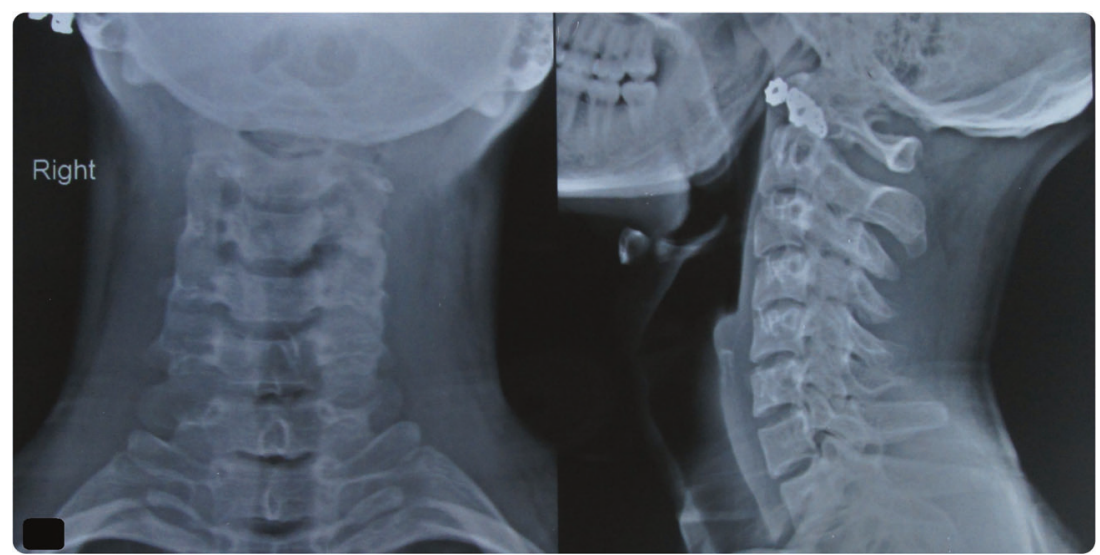

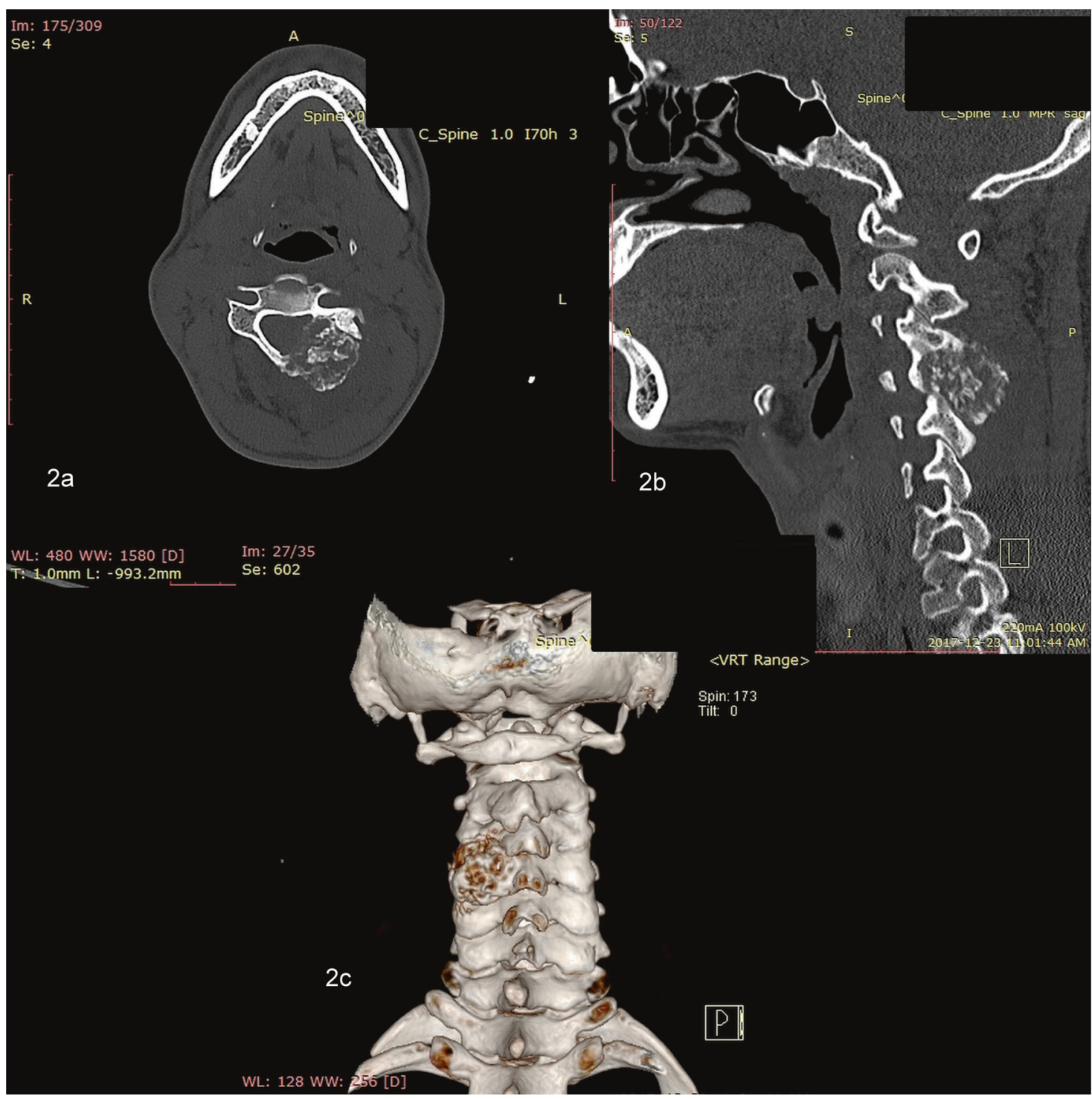

Fig. 2 CT images showing heterogeneous expansile mass arising out of the $\mathrm{C} 4$ left lamina posteriorly, also involving the lateral mass and encroaching into the canal. Intralesional septations with a sclerotic surrounding rim are seen 


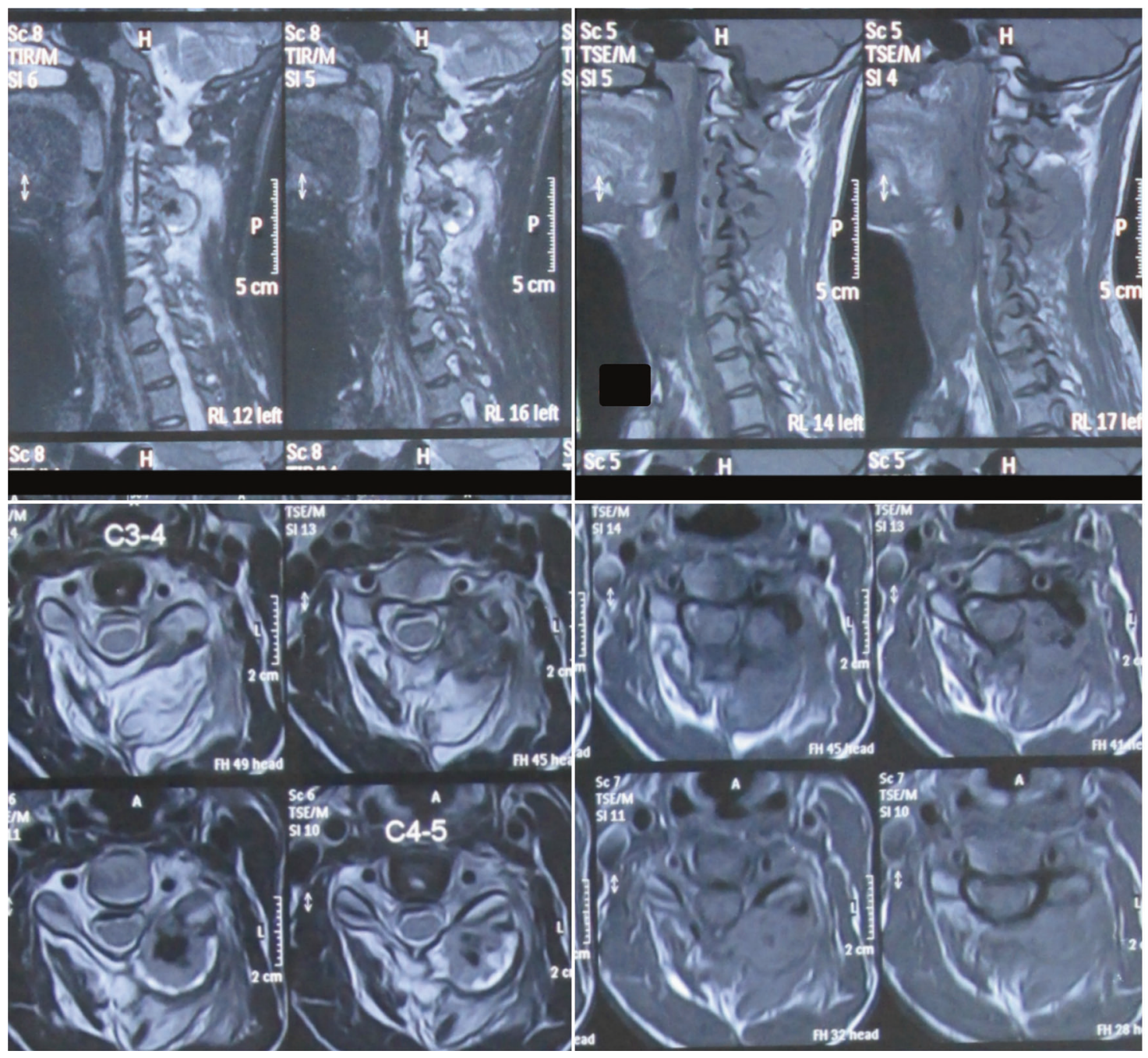

Fig. 3 MRI images showing a markedly expansile, circumscribed, ovoid, mixed lytic-sclerotic mass with dense matrix mineralization originating from left lamina of $\mathrm{C} 4$ measuring $2.6 \times 2.3 \times 1.9 \mathrm{~cm}$. The lesion was predominantly exophytic posteriorly causing elevation and displacement of the left posterior paraspinal muscles. It had a narrow zone of transition with the host bone. There were minor extensions toward the left neural foramina at $\mathrm{C} 3-\mathrm{C} 4$ and $\mathrm{C} 4-\mathrm{C} 5$, but no significant root compression, and subtle indentation of the posterior epidural space with no cord compression patient underwent an excision biopsy. Intraoperatively it was noted the tumor had involved the $\mathrm{C} 4$ left facet with erosion of the $\mathrm{C} 3-\mathrm{C} 4$ facet joint. We removed the $\mathrm{C} 4$ lamina along with the tumor mass piecemeal and curetted the pedicle and facet on left side. Since this caused potential instability in the spine, lateral mass fixation and fusion was performed from C3 to C5. Dura was decompressed completely. Postoperatively, the patient recovered uneventfully, mobilized on day 1 with a hard cervical collar for support. Postoperative neurologic examination was normal. The diagnosis on histopathological examination was osteoblastoma with ABC-like changes (Fig. 4). At 2 years follow-up, the individual was symptom free. Radiologic evaluation shows no signs of tumor recurrence with complete fusion achieved (Fig. 5).

\section{Discussion}

Osteoblastoma accounts for $\sim 1 \%$ of primary bone tumors, has a male predilection with ratio $2: 1$, and occurs in the early age group of $<30$ years. Osteoblastoma in spine usually appears in the posterior elements. Pain unresponsive to nonsteroidal anti-inflammatory drugs is the most common presenting complaint. Occasional pathological fractures have been reported due to larger size tumors. The differential diagnosis for osteoblastoma includes osteoid osteoma, chondroblastoma, and giant cell tumors, diagnosis confirmation is done by histopathological examination. Histopathologically, osteoblastoma consists of vascular connective tissue stroma with peripheral sclerotic areas. Compared with osteoid osteoma, osteoblastomas are larger 


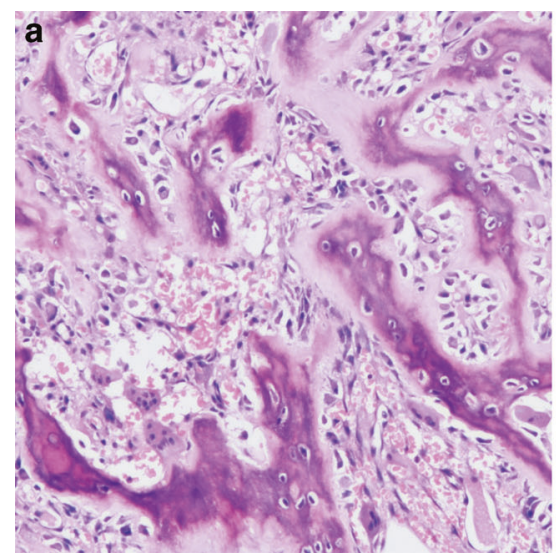

Fig. 4 Histological image showing the histopathology examination of the excised mass showed anastomosing trabeculae of osteoid and woven bone, rimmed by single layer of activated osteoblasts. Numerous osteoclasts, hemosiderophages, few lymphoid aggregates, intervening loose fibrovascular stroma between bone trabeculae,

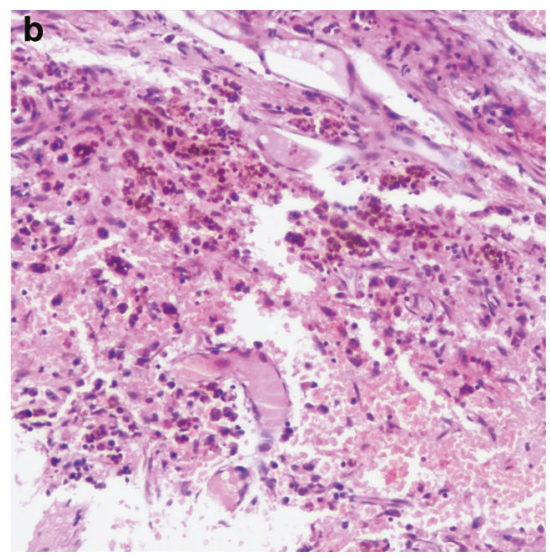

intralesional haemorrhage, and secondary aneurysmal bone cyst-like changes were seen. No marked atypia, necrosis, or atypical mitosis was present. a Histopathology H978C BS 2018 10X; b Histopathology H978F 2018 10X HEMOSID
Fig. 5 Two-year follow-up radiographs showing complete fusion of the vertebra with no sign of recurrence in the tumor bed. The spinal alignment is maintained

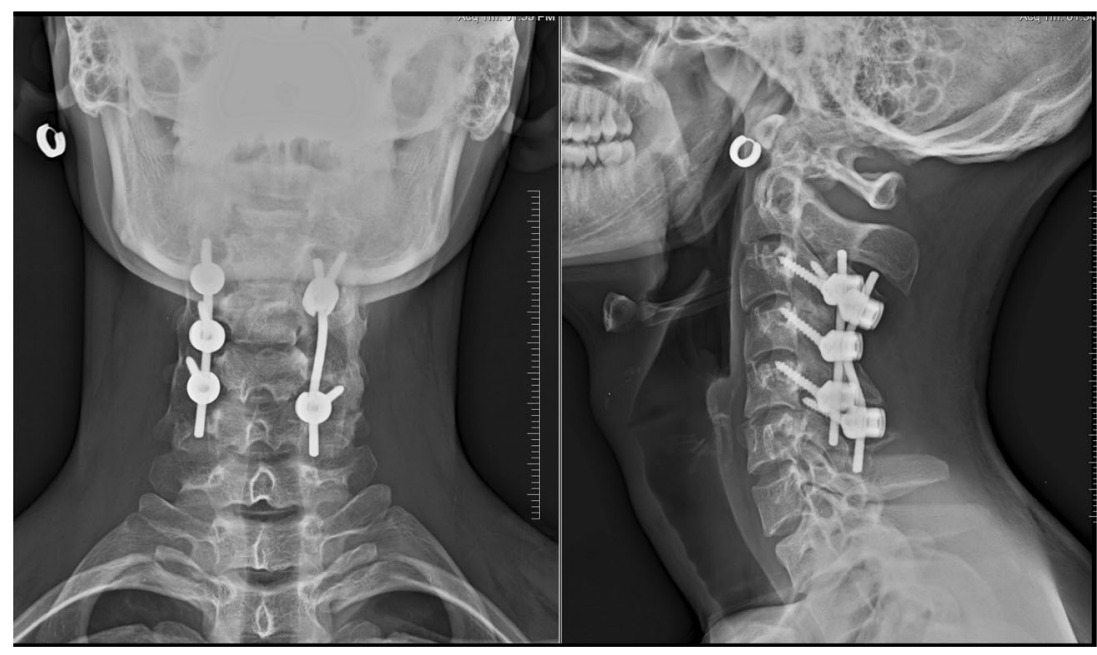

lesions with greater chances of malignant transformation. Radiological findings include matrix calcifications, radiolucent nidus, and surrounded by sclerosis.

$\mathrm{ABCs}$ are primarily vascular lesions hypothesized to arise due to a local circulation disturbance in bone resulting in increased venous pressure and dilatation of vascular structures. The majority of cases occur before 20-year age and males are predominantly affected. Localised pain, which is worse at night, is often the presenting symptom. ABCs occurring in the spine have been associated with deformity and neurological deficit, depending on the site. The radiological picture is of multiloculated lesion with fluid-fluid levels and occasional septations. Thirty percent of $\mathrm{ABCs}$ are associated with a preexisting bone tumor, e.g., osteosarcoma, giant cell tumor, fibrous dysplasia, etc. Such lesions are called secondary ABCs.

The simultaneous presence of an osteoblastoma with a secondary $\mathrm{ABC}$ arising from various bones, such as cranial fossa, ethmoid sinus, skull, or mandibular condyle, has been rarely reported [6-10]. A spinal osteoblastoma associated with secondary $\mathrm{ABC}$ is a very rare occurrence with only few cases reported in the literature. We found four cases of spinal osteoblastoma associated with secondary $\mathrm{ABC}$ in recently published studies. Three of these involved the cervical spine and one originated in lumbar vertebra [2-5] (Table 1). Osteoblastoma combined with $\mathrm{ABC}$ in the spinal column has a high rate of recurrence if incomplete resection is done $[11,12]$. Hence, we chose to do a complete excision 
Table 1 The studies reporting the osteoblastoma associated with secondary aneurysmal bone cyst (ABC) originating in spinal vertebrae

\begin{tabular}{|c|c|c|c|c|c|c|}
\hline Study & Case & Clinical features & Site of lesion & Management & $\begin{array}{l}\text { Histopathological } \\
\text { diagnosis }\end{array}$ & Follow-up \\
\hline $\begin{array}{l}\text { Tarantino } \\
\text { et al. [5] }\end{array}$ & 15 year/male & Neck pain since 6 months & C2 body & Transoral removal & $\mathrm{OB}+\sec \mathrm{ABC}$ & 1 year \\
\hline $\begin{array}{l}\text { Ramme } \\
\text { et al. [4] }\end{array}$ & 19 year/female & $\begin{array}{l}\text { Neck pain since several } \\
\text { months, headaches }\end{array}$ & $\begin{array}{l}\mathrm{C} 2 \text { posterior } \\
\text { elements }\end{array}$ & En-bloc resection & $\mathrm{OB}+\sec \mathrm{ABC}$ & 4 year \\
\hline $\begin{array}{l}\mathrm{Hu} \\
\text { et al. [2] }\end{array}$ & 11 year/male & $\begin{array}{l}\text { Torticollis and neck pain } \\
\text { since } 3 \text { years }\end{array}$ & $\begin{array}{l}\mathrm{C} 4 \text { body and } \\
\text { posterior elements }\end{array}$ & $\begin{array}{l}\text { One stage anterior }+ \\
\text { posterior resection }\end{array}$ & $\mathrm{OB}+\sec \mathrm{ABC}$ & 1 year \\
\hline $\begin{array}{l}\text { Pavanello } \\
\text { et al. [3] }\end{array}$ & 2 year/male & Back pain since 2 months & L2 boby & $\begin{array}{l}\text { Two-stage surgery } \\
\text { Posterior }+ \text { anterior }\end{array}$ & $\mathrm{OB}+\sec \mathrm{ABC}$ & 8 months \\
\hline
\end{tabular}

$O B$ osteoblastoma, $A B C$ aneurysmal bone cyst

in the present case. However, due to the anatomical location and destructive expansile nature of the tumor, spinal instability was a concern after resection. Thus, we performed instrumented fusion. We did not find any sign of tumor recurrence in this individual at 2 years follow-up.

Literature review and the present case data points toward a long history of mild local pain by the patient and the resultant delay in diagnosis leading to empirical treatment for back/neck pain. This underlines the long natural history of the disease process. Thorough surgical excision is always a challenge in spine cases due to the surrounding important structures, but meticulousness is required to prevent any recurrences. Hence, we believe it is essential to have a surgical team comprising both spine and musculoskeletal oncologic surgeons to achieve the best results.

Spinal osteoblastoma associated with an $\mathrm{ABC}$ is a rare combination in the spine, often diagnosed late due to nonspecific symptoms, but has a good prognosis if early and complete resection is performed. Our recommendation would be to thoroughly evaluate any case of neck pain, especially those with a long history of unremitting pain and, occurring in younger patients. Good clinical examination and detailed radiological evaluation will help in early diagnosis of such lesions.

\section{Compliance with ethical standards}

Conflict of interest The authors declare that they have no conflict of interest.

Publisher's note Springer Nature remains neutral with regard to jurisdictional claims in published maps and institutional affiliations.

\section{References}

1. Weber KL, Heck RKJ. Cystic and benign bone lesions. Rosemont, IL: American Academy of Orthopaedic Surgeons; 2007.

2. Hu H, Wu J, Ren L, Sun X, Li F, Ye X. Destructive osteoblastoma with secondary aneurysmal bone cyst of cervical vertebra in an 11-year-old boy: case report. Int J Clin Exp Med. 2014;7:290-5.

3. Pavanello M, Melloni I, Fiaschi P, Consales A, Piatelli G, Ravegnani $\mathrm{M}$, et al. A rare case of osteoblastoma associated to aneurysmal bone cyst of the spine. Case report. Br J Neurosurg. 2016;30:106-9.

4. Ramme AJ, Smucker JD. Balancing spinal stability and future mobility in the cervical spine: surgical treatment of a case of osteoblastoma with secondary aneurysmal bone cyst. The spine journal: official journal of the North American Spine. Society. 2011;11:e5-12.

5. Tarantino R, Piccirilli M, Anichini G, Delfini R. Benign osteoblastoma of the odontoid process of the axis with secondary aneurysmal bone cyst component: a case report. Neurosurgical Rev. 2008;31:111-5.

6. Coscina WF, Lee BC. Concurrent osteoblastoma and aneurysmal bone cyst of the ethmoid sinus: case report. J Comput Tomogr. 1985;9:347-50.

7. Han X, Dong Y, Sun K, Lu Y. A huge occipital osteoblastoma accompanied with aneurysmal bone cyst in the posterior cranial fossa. Clin Neurol Neurosurg. 2008;110:282-5.

8. Svensson B, Isacsson G. Benign osteoblastoma associated with an aneurysmal bone cyst of the mandibular ramus and condyle. Oral Surg Oral Med Oral Pathol. 1993;76:433-6.

9. Vade A, Wilbur A, Pudlowski R, Ghosh L. Case report 566: osteoblastoma of sacrum with secondary aneurysmal bone cyst. Skelet Radiol. 1989;18:475-80.

10. Wang YC, Huang JS, Wu CJ, Jeng CM, Fan JK, Resnick D. A huge osteoblastoma with aneurysmal bone cyst in skull base. Clin Imaging. 2001;25:247-50.

11. Jackson RP. Recurrent osteoblastoma: a review. Clin Orthop Relat Res. 1978;131:229-33.

12. Lucas DR, Unni KK, McLeod RA, O'Connor MI, Sim FH. Osteoblastoma: clinicopathologic study of 306 cases. Hum Pathol. 1994;25:117-34. 